\title{
Dentistry Faculty Members' Lived Experiences of Obstacles in Institutionalizing Performance Assessments to Implement Professional Competency-Based Evaluation: A Qualitative Study
}

\section{Nemat Bilan}

Medical Education Research Center, Health Management and Safety Promotion Research Institute, Department of Medical Education, School of Medicine, Tabriz University of Medical Sciences, Tabriz, Iran.

\section{Saeid Foroughi Moghaddam}

Medical Education Research Center, Health management and Safety Promotion Research Institute, Department of Medical Education, School of Dentistry, Tabriz University of Medical Sciences, Tabriz, Iran Hakimeh Hazrati

Center for Education Research Medical Sciences(CERMS), Department of Medical Education, School of medicine, Iran University of Medical Sciences, Tehran, Iran.

\section{Ramin Negahdari ( $\nabla$ ramin_n_dds@yahoo.com )}

Medical Education Research Center, Health management and Safety Promotion Research Institute, Department of Medical Education, School of Dentistry, Tabriz University of Medical Sciences, Tabriz, Iran

\section{Research Article}

Keywords: Evaluation ,Clinical Skills, Dentistry, Procedural Skills, Qualitative Study

Posted Date: January 19th, 2021

DOI: https://doi.org/10.21203/rs.3.rs-139409/v1

License: (c) (1) This work is licensed under a Creative Commons Attribution 4.0 International License. Read Full License 


\section{Abstract}

Background Evaluation is one of the main components of the learning and teaching process, which indicates the achievement rate of educational goals and also quality of education. The objective of this study was to evaluate dentistry faculty members' lived experiences of obstacles in institutionalizing performance assessments to implement professional competency-based evaluation as a qualitative study.

Methods This study was conducted with a qualitative approach by using a semi-structured interview in a focus group discussion, in which the experiences of clinical dentistry faculty members regarding obstacles of using performance assessments and faculty members' approaches to conducting professional competency-based evaluation were analyzed. The participants of the study were faculty members of the dentistry and medical education faculties. The purposive sampling technique was used and continued until reaching saturation. Five focus group discussions were conducted with 14 dentistry faculty members and three medical education faculty members. The data was analyzed by using thematic analysis.

Results Analysis of interviews yielded 450 codes which were placed in three general categories of "current condition of clinical education", "obstacles of implementing new evaluation methods", and "requirements for effective evaluation of clinical skills".

Conclusions Based on the analysis of dentistry faculty members' responses, creating changes by the faculty members appeared to be necessary. They are in fact moving towards creating changes in traditional evaluation methods. This change of paradigm requires support from the department and provision of infrastructures is deemed necessary. Also, in order to enhance motivation, spiritual support of the active faculty members should be taken into consideration and educational innovation should find its place in the promotion of faculty members.

\section{Background}

Assessing the clinical performance of trainees in the clinical workplace is considered one of the main concerns of clinical educators. On the one hand, accurate assessment of trainee performance is among the requirements to ensure physician's performance (1). Thus, one of the response items of the medical community is to obtain assurance of trainee professional competence, which is possible through designing standard competency-based evaluation. In the fields of medicine, biography skills, physical examination, communication skills with the patient, clinical judgment, professionalism and effective clinical care are among professional abilities that should be evaluated $(2,3)$. Due to Miller's pyramid, competencies are evaluated by means of performance-based assessments such as Portfolio, OSCE, DOPs, and Mini-CEX (4-6). Performance-based assessments are the only type of assessment that can evaluate clinical skills $(7,8)$, trainee behavior in dealing with the patient, communication skills and views towards treatment and diagnosis in a real-life consultation when dealing with real patients $(9,10)$, and 
provide feedback after observing their performance(11). In the field of dentistry, patients' fear and anxiety from dentistry services is very prevalent. Therefore, in addition to diagnostic and therapeutic skills, trainee's command of communication skills and management of the patient's fear and anxiety are one of the fundamental competencies that the trainee must acquire $(7,12)$. This skill can also be evaluated by means of performance assessments $(13,14)$. In most of the studies, trainees consider performance assessment as a positive experience in the evaluation process and state that receiving feedback is the most important component that leads to their learning $(15,16)$. In the field of dentistry, in various studies conducted on the application of performance assessment methods, performance assessment is considered an effective method in evaluating the clinical performance of trainees(3). For example, in the pilot study conducted by Samer Kasabah in Saudi Arabia, use of the Mini-CEX assessment method is considered an effective evaluation method by dentistry professors and students, and students consider its most important strength to be immediate feedback regarding their weaknesses and receiving constructive feedback for improving their performance (17). In the study by Ramrao Rathod, the Mini-CEX evaluation method was also considered better than other traditional evaluation methods from the viewpoint of graduate dentistry students, which helps the relationship between professor and student and also the student and patient, while also improving trainees' clinical skills and analyses(9). Considering the significance of performance assessments and their role in learning and evaluation, it has been stated in various studies that performance evaluation methods are either not completely implemented, or faculty members are not willing to implement them. For example, in the study by Behere in India, from the viewpoint of dentistry students, professors do not usually provide feedback of their performance and don't guide them towards improving their performance. In addition, in this study, dentistry professors consider one of the most important reasons for not implementing these assessments to be the fact that they are time consuming. In studies conducted in Iran, this evaluation method is considered effective, while it has some deficiencies such as disagreement among assessors and inability to provide feedback to the trainees(18). Regardless of the significance of performance assessments in approving professional competency $(19,20)$ of the trainees, much of the clinical skills assessment of dentistry students has been based on the faculty members overall perception of the students performance or assessment of their mental abilities(21). Based on a review of the literature up to 2012, there have been no studies recorded on using new evaluation methods in Iran in the field of dentistry(22). Therefore, identifying barriers in implementing them in the context of dental education in Iran is necessary in order to enhance performance assessment to fit the context of Iran's academic community. Hence, the aim of this study is to evaluate the lived experiences of dentistry faculty members in overcoming obstacles of institutionalizing performance assessments to implement professional competency-based evaluation through a qualitative study.

\section{Methods}

The main purpose of this study was to evaluate dentistry faculty members' lived experiences of obstacles in institutionalizing performance assessments to implement professional competency-based evaluation as a qualitative study. 


\section{Study Design}

The current research is a qualitative study. The purposive sampling method was used to select participants of this study and data was collected through focus group discussions (FGD) using semistructured interviews with faculty members of orthodontics and periodontics departments and the assessment committee members of the faculty of dentistry. Individuals with abundant experience in the field of clinical assessment were invited to the focus group interviews. The participants themselves agreed upon the time and location of FGD sessions so that faculty members could participate in these sessions without any distractions. Prior to staring the sessions, an interview guideline was provided including a number of open-ended questions. Among the questions were: 1) Please state your experiences regarding the current clinical skills assessment condition in the orthodontic and restorative dentistry department. 2) According to multiple years of experience you have acquired, what are the most important obstacles in using new evaluation methods for clinical skills in the field of dentistry?

Prior to the beginning of each session, consent forms were obtained from all participants and they were given explanations of the session objectives and notified that the information provided would remain confidential. Participants were informed that their participation is voluntary and they may leave the session whenever they feel necessary. Interviews were recorded with consent obtained from participants. After the end of each session, interviews were transcribed word for word and listened to numerous times in order to obtain data immersion. Data analysis was conducted concurrently with data collection and the results of analyses for each session were used as a guideline for the following sessions. The interview sessions continued until reaching saturation, and FGDs reached saturation after 5 sessions.

\section{Study Participants}

14 faculty members from the orthodontics and dental prostheses department and three faculty members from the medical education department participated in the focus group discussion interviews. The social/personal information of participants is provided in the following table. (Table 1) 
Table 1

Social/Personal Information of Study Participants

\begin{tabular}{|c|c|c|c|c|}
\hline & Gender & Age & Work Experience & Scientific ranking \\
\hline & & $30-40=2$ & $5-15=3$ & \\
\hline \multirow[t]{3}{*}{ Orthodontics } & Male $=5$ & $40-50=3$ & $15-25=3$ & Assistant Professor $=5$ \\
\hline & Female $=3$ & $50-60=3$ & $25-35=2$ & Associate professor $=3$ \\
\hline & & $30-40=3$ & $5-15=3$ & \\
\hline \multirow[t]{2}{*}{ Dental Prostheses } & Male $=3$ & $40-50=2$ & $15-25=2$ & Assistant professor $=3$ \\
\hline & Female $=3$ & $50-60=1$ & $25-35=1$ & Associate professor $=3$ \\
\hline \multirow[t]{2}{*}{ Medical Education } & Male $=2$ & $40-45=2$ & $15-25=2$ & Assistant professor $=2$ \\
\hline & Female $=1$ & $45-60=2$ & $25-35=1$ & Professor $=1$ \\
\hline
\end{tabular}

\section{Data Analysis Method}

Data analysis was conducted using the common content analysis method concurrently with data collection. That is, the interviews were initially transcribed and the audio recording of interviews was listened to numerous times in order to better understand the content.

Then the first phase of the coding process began with emphasis on the explicit and implicit content by means of identifying and highlighting the sentences and paragraphs of the unit of analysis. Each unit of analysis is given a code and sub-codes are extracted. Then, codes are reduced to sub-categories and categories based on differences and similarities. Codes were continuously controlled and in the event of any contradiction, this incongruity would be resolved through discussions. Then, an attempt was made to obtain an overall picture of the topic at hand through creating a relationship between the categories(23).

\section{Rigor Of Study}

In order to determine the validity of the data in the study, continuous evaluation of the data and concurrent data analysis was used. After collecting data and reviewing codes extracted by participants, the data analysis process was carried out with the help of the research team $(\mathrm{N}, \mathrm{B})$, and the data was continuously controlled and analyzed. The extracted codes were returned to the participants for approval in order to certify an accurate understanding of the participants' viewpoints. Details of the research were accurately documented and phases of the research were explained from beginning to end in details so that the external observer could conduct an evaluation. In addition, an attempt was made to use appropriate and extensive samples considering individual characteristics such as age, work experience and scientific ranking in order to have access to data diversity.

\section{Results}


450 codes were obtained from analyses of the interviews in three overall categories; "current condition of clinical education", "obstacles in implementing new evaluation methods", approaches to improving the performance assessment of dentistry students".

In the realm of "current condition of clinical education" two categories of "phase of accepting the necessity for creating changes in clinical skill evaluation methods by dentistry faculty members", and "beginning the transition stage from traditional clinical evaluation methods to new evaluation methods" were obtained (Table 2).

Viewpoints of dentistry faculty members in the category "phase of accepting the necessity for creating changes in clinical skills evaluation methods by dentistry faculty members"

Participant Number 2 stated that: "Training and evaluation is done subjectively and is not consistent to a certain extent. As a result, it seems that both the grade and evaluation quality are subjective, do not have adequate reliability and depend on the professor's opinion."

Participant Number 5 stated that: "Quality of assessments is average in the current state and is a long way from reaching an ideal state. Sometimes we are not sure whether all students have acquired all the necessary skills or not? In my opinion, the tools and skills that should be acquired by a General Dentistry student need to be specified, actually there is no rule of thumb and we need to pass this stage."

Viewpoints of dentistry faculty members in the category "beginning the transition stage from traditional clinical evaluation methods to new evaluation methods"

Participant Number 11 stated that: "The DOPs method is used for evaluation of practical skills in the prosthesis unit to a certain extent; however, it is done in a traditional manner. Standard checklists have not been designed and some of the professors implement their own creativity in evaluating some skills using DOPs."

Participant Number 9 stated that: "In the removable prosthesis unit, evaluation of skills is conducted by the professor during different phases of the task and the student is given feedback. Also, the students final grade is calculated with reference to the logbook at the end of the term and the Mini-CEX method is actually being routinely carried out, and of course it requires greater organization". 
Table 2

Dentistry faculty members' perception of the current situation of clinical skills evaluation in the orthodontic prosthesis department

Category
Current situation of
clinical skills evaluation
in the orthodontic
prosthesis department

Current situation of in the orthodontic prosthesis department

\section{Sub-category}

Admission stage: necessity of creating changes in clinical skills evaluation methods by dentistry faculty members

\section{Open code?}

- Informality between clinical evaluations and ideal conditions

- Subjectivity of teaching and clinical evaluation

- Evaluating clinical skills from activities performed in the dominant method for clinical assessment

- Inadequate standards for assessments

- Necessity of changing evaluations due to the decrease in quality of clinical skills evaluation

Beginning of the transfer from traditional clinical skills evaluation methods to innovative evaluation methods
- Spontaneous use of the DOPS method in the first phase for evaluating practical skills

- Moving towards improved quality by holding integrated assessments (practical + theoretical)

- A number of clinical skills are not included in the OSCE assessment and the need to focus on procedural assessments

Six categories are identified in the realm of "obstacles in implementing new evaluation methods"; "the essence of clinical skills evaluation", "faculty members lack of awareness regarding the implementation of new evaluation methods", "faculty members resistance in making use of new evaluation methods", "poor supervision of clinical evaluation", "inadequate infrastructures for implementing new assessments", and "inadequate system of feedback for faculty members evaluation performance". (Table 3 )

Viewpoints of dentistry faculty members in the category "essence of clinical skills evaluation"

Participant number 10 stated that: "Each skill has numerous stages and designing a checklist based on each skill is very time-consuming. On the other hand, there are many skills and such an assessment cannot be designed for all skills."

Participant number 8 stated that: "In order to evaluate some of the skills, the presence of the patient or a simulated patient is necessary, and finding a patient with the scenario in mind can be quite difficult. Also, 
if we want to use a simulated patient, training requires great costs and we are often not given adequate financial support to do so."

Viewpoints of dentistry faculty members in the category "faculty members lack of awareness regarding implementation of new evaluation methods"

Participant number 9 stated that: "Less research is conducted in the field of educational issues... and our knowledge regarding experiences of different fields and other universities regarding the design of these assessments is not sufficient."

Participant number 2 stated that: "Faculty members are not acquainted with all evaluation methods, in fact, they follow in the footsteps of their own professors and do not have the motivation to enhance their methods or even use other methods."

Viewpoints of dentistry faculty members in the category "faculty members' resistance towards making use of new evaluation methods"

Participant number 12 stated that: "faculty members are resistant towards new methods of evaluation and .... faculty members that use innovative methods are considered to be breaking the tradition and are prohibited from promoting these methods."

Participant number 3 stated that: "With the integration of treatment and education, faculty members workload is very high and they spend less time on education and evaluation."

Viewpoints of dentistry faculty members in the category "weak supervision of clinical evaluation"

Participant number 3 stated that: "Educational supervisors have fallen short in their supervision and when faculty members notice that they do not have to be responsive for their performance, each will perform subjectively."

Participant number 12 stated that: "Until now, the university has not developed any regulations for how to conduct skills evaluation and to create a unified procedure of evaluation. Therefore, the subjective performance of the faculty members is quite natural."

Viewpoints of dentistry faculty members in the category "Inadequate infrastructures for implementing innovative evaluation"

Participant number 10 stated that: "There is great number of students and the number of sessions for each section is limited... evaluating this number of students using DOPs during this limited duration of time is not possible."

Viewpoints of dentistry faculty members in the category "inadequate system of feedback for faculty members performance evaluation" 
Participant number 8 stated that: "The university's response towards all faculty members is somewhat the same and the system for providing incentives and motivation is not very efficient. Is it too much to ask for at least a written letter of encouragement for adding creativity to the program?"

Viewpoints of dentistry faculty members in the category "Poor physical facilities"

Participant number 8 stated that: "the test hall is very small and does not have adequate facilities to conduct clinical assessments. We are sometimes faced with lack of supplies to carry out certain treatment procedures." 
Table 3

Obstacles of Effective Clinical Skills Evaluation from the viewpoint of faculty members in the faculty of orthodontics and prosthesis

\begin{tabular}{|c|c|c|}
\hline Category & Sub-category & Open Code \\
\hline \multirow{18}{*}{$\begin{array}{l}\text { Obstacles in effective } \\
\text { clinical skills evaluation } \\
\text { in the field of dentistry }\end{array}$} & \multirow[t]{6}{*}{$\begin{array}{l}\text { Essence of clinical skills } \\
\text { evaluation }\end{array}$} & $\begin{array}{l}\text { - Variety of clinical skills in the } \\
\text { department }\end{array}$ \\
\hline & & $\begin{array}{l}\text { - Difficulty with categorizing skills and } \\
\text { adequate scoring }\end{array}$ \\
\hline & & $\cdot$ High costs \\
\hline & & $\begin{array}{l}\text { - Numerous practical stages and required } \\
\text { skills }\end{array}$ \\
\hline & & $\begin{array}{l}\text { - Presence of the patient is required in } \\
\text { evaluating some skills }\end{array}$ \\
\hline & & $\begin{array}{l}\text { - High stress rate of these assessments } \\
\text { for the student }\end{array}$ \\
\hline & \multirow{2}{*}{$\begin{array}{l}\text { Faculty members lack of } \\
\text { awareness regarding } \\
\text { innovative methods of } \\
\text { evaluation }\end{array}$} & $\begin{array}{l}\text { - Lack of knowledge and awareness or } \\
\text { experience regarding similar cases in } \\
\text { other fields and universities }\end{array}$ \\
\hline & & $\begin{array}{l}\text { - Faculty member unfamiliarity with all } \\
\text { evaluation methods }\end{array}$ \\
\hline & \multirow[t]{5}{*}{$\begin{array}{l}\text { Faculty members resistance } \\
\text { towards using innovative } \\
\text { evaluation methods }\end{array}$} & $\begin{array}{l}\text { - Unnecessary emphasis on written } \\
\text { exams for clinical assessment }\end{array}$ \\
\hline & & - High workload \\
\hline & & $\begin{array}{l}\text { - Conducting laboratory duties along with } \\
\text { clinical duties }\end{array}$ \\
\hline & & $\begin{array}{l}\text { - Some faculty members do not use } \\
\text { checklists and logbooks }\end{array}$ \\
\hline & & $\begin{array}{l}\text { - Lack of coordination among faculty } \\
\text { members of one department }\end{array}$ \\
\hline & \multirow[t]{5}{*}{$\begin{array}{l}\text { Poor supervision of clinical } \\
\text { evaluation }\end{array}$} & $\begin{array}{l}\text { - Inadequate and inefficient training and } \\
\text { evaluation of some faculty members } \\
\text { (qualitatively and quantitatively) }\end{array}$ \\
\hline & & - No guidelines for scoring each skill \\
\hline & & $\begin{array}{l}\text { - No unified procedure in training and } \\
\text { evaluation }\end{array}$ \\
\hline & & $\begin{array}{l}\text { - Conducting subjective evaluations of } \\
\text { students performance }\end{array}$ \\
\hline & & $\begin{array}{l}\text { - Lack of emphasis on fundamental } \\
\text { educational priorities in skills evaluation }\end{array}$ \\
\hline
\end{tabular}




\begin{tabular}{|c|c|c|}
\hline Category & Sub-category & Open Code \\
\hline & \multirow{7}{*}{$\begin{array}{l}\text { Poor infrastructures for } \\
\text { implementing innovative } \\
\text { assessments }\end{array}$} & $\begin{array}{l}\text { - Unbalanced and high ratio of students } \\
\text { to professor in the department }\end{array}$ \\
\hline & & $\begin{array}{l}\text { - Insufficient time for practice or } \\
\text { innovative assessments due to great } \\
\text { number of students }\end{array}$ \\
\hline & & $\begin{array}{l}\text { - Limited number of sessions compared } \\
\text { to number of students }\end{array}$ \\
\hline & & $\begin{array}{l}\text { - Lack of evaluation briefings in the } \\
\text { department }\end{array}$ \\
\hline & & - Lack of pre-determined program \\
\hline & & $\begin{array}{l}\text { - Lack of sufficient independence for } \\
\text { department supervisors }\end{array}$ \\
\hline & & - Insufficient time \\
\hline & \multirow[t]{3}{*}{$\begin{array}{l}\text { Poor system of feedback for } \\
\text { faculty members } \\
\text { performance evaluation }\end{array}$} & $\begin{array}{l}\text { - Active faculty members implementing } \\
\text { innovative evaluation methods do not } \\
\text { receive feedback from the university }\end{array}$ \\
\hline & & $\begin{array}{l}\text { - Indifferent reaction of university towards } \\
\text { active faculty members and those } \\
\text { performing traditionally }\end{array}$ \\
\hline & & $\begin{array}{l}\text { - Having an outlook of breaking traditions } \\
\text { if faculty members perform differently }\end{array}$ \\
\hline & \multirow[t]{3}{*}{ Poor physical facilities } & - Lack of space and facilities \\
\hline & & $\begin{array}{l}\text { - Low number of patients due to long } \\
\text { admission process for patients }\end{array}$ \\
\hline & & $\begin{array}{l}\text { - Lack of simulation-patients due to high } \\
\text { costs }\end{array}$ \\
\hline
\end{tabular}

In the realm of "Necessity for implementing innovative evaluation methods", five categories including: "providing physical facilities", "making use of an efficient workforce", "planning and organizing for implementation of innovative evaluation methods", "structural changes for implementing innovative evaluation methods" and "preparing infrastructures to implement innovative evaluation method" were obtained (Table 4).

Viewpoints of dentistry faculty members in the category "providing physical facilities"

Participant number 10 stated that: "... the required facilities are not provided to work efficiently; for example, infection control requires more facilities such as turbines or an individual hand pass for each patient." 
Viewpoints of dentistry faculty members in the category "making use of an efficient workforce"

The participant stated that: "faculty member recruitment necessitates filtering so that faculty members with high capabilities are recruited, preferably graduates of Type 1 universities."

Viewpoints of dentistry faculty members in the category "planning and organizing to implement innovative evaluation methods"

Participant number 5 stated that: "Empowerment courses are a necessity for faculty members, preferably during a short duration of time so that we can participate in workshops in between our duties, while still being continuous."

Participant number 1 stated that: "evaluation method workshops should be held so that faculty members can become familiar with how to design checklists, scenarios, implement and score them. Some faculty members are not familiar with designing scenarios and think that if they place a cliché in one station, conduct a performance assessment which is actually similar to multiple choice tests, it is only station to station."

Viewpoints of dentistry faculty members in the category "structural changes to implement innovative evaluation methods"

The participant stated that: "the grade must be based on type of behavior and encounter with the patient, maintaining health and safety of the patient and proficiency in educational duties. It is done more subjectively."

Participant number 13 stated that: "limitation of number of students in order to perform and accurately evaluate all skills for each student during the time given. However, this decision is made at the Ministry of Health and the university can declare its opinion to the Ministry."

Viewpoints of dentistry faculty members in the category "preparing infrastructures to implement innovative evaluation methods"

\section{Participant number 3}

In order to conduct standard and fair evaluation among students, evaluation should be done based on a specified checklist, because students take the courses with different professors.

\section{Participant Number 7}

"the department requires a unified guideline for the above objective and this has not been done thus far." 
Table 4

Requirements of an effective clinical skills evaluation in the orthodontics prosthesis department from the viewpoint of faculty members of the orthodontic and prosthesis group

\begin{tabular}{|c|c|c|}
\hline Category & Sub-category & Open Code \\
\hline \multirow{19}{*}{$\begin{array}{l}\text { Necessity for } \\
\text { effective } \\
\text { evaluation of } \\
\text { clinical skills }\end{array}$} & \multirow[t]{2}{*}{$\begin{array}{l}\text { Providing physical } \\
\text { facilities }\end{array}$} & $\begin{array}{l}\text { - Providing necessary facilities such as a standard } \\
\text { test hall for clinical assessment }\end{array}$ \\
\hline & & $\begin{array}{l}\text { - Providing fundamental facilities to conduct } \\
\text { clinical duties }\end{array}$ \\
\hline & \multirow[t]{2}{*}{$\begin{array}{l}\text { Making use of an efficient } \\
\text { workforce }\end{array}$} & $\begin{array}{l}\text { - Recruiting faculty members with adequate } \\
\text { capabilities }\end{array}$ \\
\hline & & - Standardizing the number of faculty members \\
\hline & \multirow{5}{*}{$\begin{array}{l}\text { Planning and organizing to } \\
\text { implement innovative } \\
\text { evaluation methods }\end{array}$} & $\begin{array}{l}\text { - Acquainting faculty members with evaluation } \\
\text { methods }\end{array}$ \\
\hline & & $\begin{array}{l}\text { - Holding one-hour courses on a continuous basis, } \\
\text { instead of daily courses }\end{array}$ \\
\hline & & - Determining necessary learning skills \\
\hline & & - Sufficient time for evaluating each skill \\
\hline & & - Allocating more time for the examiner \\
\hline & \multirow[t]{4}{*}{$\begin{array}{l}\text { Structural changes for } \\
\text { implementing innovative } \\
\text { evaluation methods }\end{array}$} & $\begin{array}{l}\text { - Scoring based on behavior and encounter with } \\
\text { the patient, maintaining health and safety of the } \\
\text { patient }\end{array}$ \\
\hline & & - Standardizing the number of students \\
\hline & & $\begin{array}{l}\text { - Expanding the evaluation center in order to } \\
\text { coordinate evaluation activities }\end{array}$ \\
\hline & & $\begin{array}{l}\text { - Determining and implementing policies of the } \\
\text { evaluation center Distribution of patients among } \\
\text { students at the beginning of the term }\end{array}$ \\
\hline & \multirow{6}{*}{$\begin{array}{l}\text { Preparing infrastructures } \\
\text { for implementing } \\
\text { innovative evaluation } \\
\text { methods }\end{array}$} & $\begin{array}{l}\text { - Designing a unified checklist in order to } \\
\text { standardize clinical evaluations }\end{array}$ \\
\hline & & $\begin{array}{l}\text { - Developing a unified guideline for implementing } \\
\text { clinical skills evaluation }\end{array}$ \\
\hline & & - Developing common criteria for scoring \\
\hline & & $\begin{array}{l}\text { - Using a checklist and logbook to record clinical } \\
\text { evaluation immediately after each training session }\end{array}$ \\
\hline & & $\begin{array}{l}\text { - Better coordination among faculty members } \\
\text { teaching each practical course }\end{array}$ \\
\hline & & $\begin{array}{l}\text { - Obligation of faculty members to qualitatively } \\
\text { and quantitatively use practical training sessions } \\
\text { throughout the term }\end{array}$ \\
\hline
\end{tabular}




\section{Discussion}

The aim of this study was to evaluate the obstacles and requirements for implementing performance assessments in the evaluation of General Dentistry students based on the lived experiences of faculty members at Tabriz University of Medical Sciences. According to analyses of interviews related to current conditions, two categories of "acceptance phase indicating the necessity to create changes" and "beginning of transition phase from traditional methods of clinical skills evaluation to innovative evaluation methods" were obtained. In fact, the deficiencies in clinical skills evaluation and incompetence in obtaining required skills by faculty members and students have been acknowledged. The results of some studies also indicate the lack of students' efficient skills and inadequate evaluation of trainees, whereas in the study by Sodagar et al. in the field of dentistry, trainees had not obtained the necessary competencies in conducting some basic skills such as ability to present the treatment plan and controlling children's behavior, and this condition of clinical skills indicates poor training and evaluation of their basic skills(24).

In studies conducted on the quality of clinical skills evaluation of trainees, dentistry students have also emphasized the necessity for expanding procedural skill assessments in order to enhance the evaluation/training aspect(25).

In the study by Singh, using these assessments was considered effective in increasing performance skills and implementing such assessments were required from the first clinical encounters(25). Making use of innovative clinical assessments such as Mini-CEX and DOPs are somewhat reassuring for the faculty members to ascertain skills acquisition required by their trainees(17). Therefore, this study indicated the acceptance of change in innovative evaluation methods from both the student and faculty members and the preparedness to accept new methods of evaluation. This is while some studies carried out in Iran suggest the beginning of a movement towards changes in evaluation procedures from subjective-based evaluations by the faculty member towards standard performance assessments. In the study conducted by Kouhpayehzadeh et al. in three universities of Tehran, Iran and Shahid Beheshti Universities of Medical Sciences, after multiple-choice assessments in these universities, OSCE, logbook, portfolio and 360 degrees were used for evaluating performance skills(26). In various other studies conducted in developed countries, making use of performance assessment methods are considered beneficial (13). In addition, in the study by Lohe et al., a meaningful correlation was observed in trainees' scores in the first encounter to the fourth encounter by using the Mini-Cex assessment, and trainees' scores increased after four encounters(27). Students considered this method to be valuable for evaluating clinical competencies at the level of General Dentistry that can prepare them for the specialization (27). Considering the obstacles in using innovative evaluation methods, six categories were obtained: "the complex and time-taking essence of clinical skills evaluation", "faculty members unawareness regarding the implementation of innovative evaluation methods", "resistance of faculty members in using innovation evaluation methods", "poor supervision of clinical assessments", "poor infrastructures for implementing innovative 
assessments", "poor feedback system for faculty members performance evaluation." Most faculty members acknowledged that innovative evaluation methods are essentially time-taking and difficult to design and this feature results in their refraining from the design and use of such assessments $(18,28)$. In the study by Faryab and Sinai, the most important issue related to the overall structure of performance assessments was having an experienced team of examinees that should be familiar with these methods and can perform proficiently in designing checklists, without disagreements among examinees. The stressful essence of these assessments is among other features, whereas they are conducted under the supervision of the professor and result in high stress and anxiety for the student(29). Therefore, most professors suggest that these assessments be used as procedural assessments so that they can have more educational aspects and provide feedback in order to resolve weaknesses(30). This is while in various studies students consider the advantage of these assessments to be the feedback and improving their weaknesses $(12,31)$.

Another obstacle in making use of innovative evaluation methods is lack of clinical supervision. In the current educational system, evaluation of faculty members has more of a quantitative aspect and is mostly based on evaluation forms designed based on the evaluation system and their performance is not evaluated in the field. The system of promotion is mostly research based and is conducted according to research performance and number of publications, while teaching and training have the lowest score in the promotion process. Thus, faculty members spend most of their time and energy on research (32). As a result, in order to change professors' viewpoints, supervision and motivation should be enhanced, so that they will become interested in using these assessments. Empowering faculty members and training expert examinees is the next stage that the university may take to facilitate the use of innovative evaluation methods. However, empowerment courses should be provided based on needs analysis. This is while faculty members, having taken empowerment courses, still felt their real needs regarding design and implementation of the assessment have not be resolved. Therefore, faculty member empowerment facilities should be provided regarding the design and implementation of assessments based on needs in the field of dentistry.

\section{Conclusions}

Changes in evaluation methods are one of the necessities of responding to the community's needs. The medical community should be directed towards a competency-based curriculum, especially in fields like dentistry that are procedure-based. Assurance of acquired skills is among faculty members' concerns and at other levels are the university and people. Using performance-based assessments instead of multiplechoice assessments can be a step forward in training skillful students with the professional competency necessary for providing services to the community.

\section{Abbreviations}

OSCE: The Objective Structured Clinical Examination 
DOPs: Direct Observation of Procedural Skills

Mini-CEX: Mini Clinical Evaluation Exercise

FGD: Focus Group Discussions

\section{Declarations}

\section{Ethical Approval and Consent to Participate:}

This study was approved by the Research Ethics Committee of Tabriz University of Medical Sciences (IR.TBZMED.REC.1397.253). Data collection was carried out after obtaining verbal and signed informed consent in accordance with the Deceleration of Helsinki from participants. The informed consent process provided participants the opportunity to ask questions and consider all options. Participants could refuse to participate or withdraw from the study at any time. Each interview was recorded by a digital sound recorder after obtaining the participants' permission, and important notes were taken.

\section{Consent for publication:}

Informed Consent for publication was obtained from each participant.

\section{Availability of Data and Material:}

The data that support these findings are available [without personal details participants] but restrictions apply to the availability of these data, which were used under license for the current study, and so are not publicly available. Data are however available from the corresponding author upon reasonable request.

\section{Competing interests:}

No competing interests.

\section{Funding:}

This research was supported and granted by the Medical Education Research Center of Tabriz University of Medical Sciences, Tabriz, Iran. The funder has not responsibility in the design of the study, data collection, analysis, and in the writing of the manuscript.

\section{Authors' Contributions:}

$\mathrm{RN}, \mathrm{HH}, \mathrm{SF}$, and NB were involved in this study for designing and drafting the research and the manuscript. NB was responsible for coordinating the study. RN and SF interviewed the participants. RN, $\mathrm{HH}, \mathrm{SF}$, and NB commented on the coding process. $\mathrm{HH}$ wrote the first and second draft of the paper. RN, $S F$, and NB reviewed the first and second draft of the paper and improved it. All authors have read and approved the final version of the manuscript. 
Acknowledgements:

The authors would like to thank Tabriz University of Medical Sciences for supporting and granting this research as a part of a MS thesis in medical education.

\section{References}

1. Allery L. Assess trainees in the clinical workplace using the Mini-CEX (mini clinical evaluation exercise). Education for Primary Care. 2006;17(3):270-4;doi: 1080/14739879.2006.11864073.

2. Hsu T-C, Tsai SS-L, Chang JZ-C, Yu S-H, Lai EH-H, Lin C-P. Core clinical competencies for dental graduates in Taiwan: Considering local and cultural issues. Journal of Dental Sciences. 2015;10(2):161-6;doi: 10.1016/j.jds.2014.05.005.

3. Gerhard-Szep S, Guentsch A, Pospiech P, Söhnel A, Scheutzel P, Wassmann T, et al. Assessment formats in dental medicine: An overview. GMS journal for medical education. 2016;33(4); doi: 10.3205/zma001064.

4. Miller GE. The assessment of clinical skills/competence/performance. Academic medicine. 1990;65(9):S63-7.

5. Cantillon P, Wood DF, Yardley S. ABC of learning and teaching in medicine: John Wiley \& Sons; 2017.

6. Hosseini-Qavam-Abad L, Asghari F, Bandehagh A, Bigdeli S, Najafpour S. Designing a Tool to Assess Medical Students' Knowledge and Attitudes of Confidentiality and Disclosure of Patient Information. Journal of Medical Education. 2016;15(2).

7. Kalsi $\mathrm{H}$, Kalsi J, Fisher N. An explanation of workplace-based assessments in postgraduate dental training and a review of the current literature. British dental journal. 2013;215(10):519-24; doi: 10.1038/sj.bdj.2013.1098

8. Dent J, Harden RM, Hunt D. A practical guide for medical teachers: Elsevier health sciences; 2017.

9. Rathod SR, Kolte A, Shori T, Kher V. Assessment of postgraduate dental students using mini-clinical examination tool in periodontology and implantology. Journal of Indian Society of Periodontology. 2017;21(5):366; doi: 10.4103/jisp.jisp_293_16.

10. Dutile FNE. Legal Education and Lawyer Competency. Curricula for Change.

11. Fluit C. Evaluation and feedback for effective clinical teaching: [SI: sn]; 2013.

12. Edgar S, Lamb I. Teaching clinical and communication skills and giving effective feedback. Medical Education: The State of the Art NY: Oxford Nova Science Publisher. 2010.

13. Behere R. Introduction of Mini-CEX in undergraduate dental education in India. Education for Health. 2014;27(3):262.

14. Fitch C, Malik A, Lelliott P, Bhugra D, Andiappan M. Assessing psychiatric competencies: what does the literature tell us about methods of workplace-based assessment? Advances in Psychiatric Treatment. 2008;14(2):122-30; doi: 10.1192/apt.bp.107.003871 
15. Deshpande S, Pande N, Radke U, Jaiswal P, Rathi A, Sahni S. Evaluation of Mini Clinical Evaluation Exercise (Mini-CEX) for post-graduate students in Prosthodontics: Student and Faculty Perceptions. MedEdPublish. 2018;7; doi: 10.15694/mep.2018.0000014.1

16. Zamanzadeh V, Abdollahzadeh F, Lotfi M, Aghazadeh A. Assessing clinical education fields from the viewpoints of nursing and midwifery instructors in Tabriz University of Medical Sciences, 2006. Iranian Journal of Medical Education. 2008;7(2):299-307.

17. Kasabah S, Gokul G. Mini clinical evaluation exercise in dental education in Kingdom of Saudi Aabia: a pilot study. Int J Cur Res Rev. 2017;9(2):20-4.

18. Khanghahi ME, Azar FEF. Direct observation of procedural skills (DOPS) evaluation method: Systematic review of evidence. Medical journal of the Islamic Republic of Iran. 2018;32:45; doi: 10.14196/mjiri.32.45.

19. Kingsley K, O'Malley S, Stewart T, Howard KM. Research enrichment: Evaluation of structured research in the curriculum for dental medicine students as part of the vertical and horizontal integration of biomedical training and discovery. BMC Medical Education. 2008;8; doi: 10.1186/1472-6920-8-9.

20. Yazdani R, Zahra Mohebbi S, Mortazavi M, Madankan D. Evaluation of Clinical Competency and the Influential Factors in Dentistry Students Using the Self-assessment Method. Journal of Mashhad Dental School. 2018;42(4):348-55.

21. Norcini JJ, Blank LL, Duffy FD, Fortna GS. The mini-CEX: a method for assessing clinical skills. Annals of internal medicine. 2003;138(6):476-81; doi: 10.7326/0003-4819-138-6-200303180-00012.

22. Akbari M, Mahavelati Shamsabadi R. Direct Observation of Procedural Skills (DOPS) in Restorative Dentistry: Advantages and Disadvantages in Student's Point of View. Iranian Journal of Medical Education. 2013;13(3):212-20.

23. Barnett-Page $E$, Thomas J. Methods for the synthesis of qualitative research: a critical review. BMC medical research methodology. 2009;9(1):1-11; doi: 10.1186/1471-2288-9-59.

24. Sodagar A, Jafari A, Sedighpour L, Ghahremani Gol H. Assessment of the clinical skills of dental students in the dept. of pediatric dentistry. Iranian Journal of Pediatric Dentistry. 2015;10(2):81-8; doi: 10.29252/ijpd.10.2.81.

25. Singh G, Kaur R, Mahajan A, Thomas AM, Singh T. Piloting direct observation of procedural skills in dental education in India. International Journal of Applied and Basic Medical Research. 2017;7(4):239; doi: 10.4103/ijabmr.IJABMR_54_17.

26. Kouhpayezadeh J, Dargahi H, Soltani Arabshahi K. Clinical assessment methods in medical sciences universities of Tehran-Clinical instructors' viewpoint. Hormozgan Medical Journal. 2012;16(5):395402.

27. Lohe V, Hande A, Bhowate R, Dangore S, Sune R. Evaluation of Final BDS students using mini-CEX for assessing the clinical skills in Oral Medicine. Journal of Education Technology in Health Sciences. 2016;3(2):68-73; doi:10.5958/2393-8005.2016.00011.5. 
28. Gharib M, Rabieian M, Salsali M, Hadjizadeh E, Kashani AS, Khalkhali H. Critical Thinking Skills and Critical Thinking Dispositions in Freshmen and Senior Students of Health Care Management. Iranian journal of medical education. 2009;9(2).

29. Faryab J. Sinai N. Kerman dental school students in the clinical evaluation of the Objective Structured Clinical Examination (OSCE). Journal of Kerman Medical Education Development Center. 2008;6(1):34-9.

30. Fluit C, Bolhuis S, Grol R, Ham M, Feskens R, Laan R, et al. Evaluation and feedback for effective clinical teaching in postgraduate medical education: Validation of an assessment instrument incorporating the CanMEDS roles. Medical teacher. 2012;34(11):893-901; doi: 10.3109/0142159X.2012.699114

31. Lokko HN, Gatchel JR, Becker MA, Stern TA. The Art and Science of Learning, Teaching, and Delivering Feedback in Psychosomatic Medicine. Psychosomatics. 2016;57(1):31-40; doi: 10.1016/j.psym.2015.09.006

32. Ahmady S, KAjeh jashoghani M, Mohammadimehr M. Explaining the Expectations and Views of the Faculty Members in Relation to the Educationa Development Centers. Research in Medical Education; doi: 2019;11(3):39-48 10.29252/rme.11.3.39

\section{Supplementary Files}

This is a list of supplementary files associated with this preprint. Click to download.

- Consentform1.pdf 